\title{
An Electric Public Transportation Vehicle Modelling and Comparison with Conventional Diesel Vehicle
}

\author{
Goşenay Zeynep AVCI ${ }^{1}$ Orkun ÖZENER ${ }^{2}$ \\ ${ }^{1}$ Automotive Sciences Subdivision, Department of Mechanical Engineering, Y1ldı Technical University \\ İstanbul, Turkey
}

\begin{abstract}
Public transportation which travels around inner city routes is showing great importance in terms of air pollution arousing from internal combustion engines. In this context, lots of different solution are developed by the scientific and industrial community. Usage of electric vehicles which tank to wheel emissions are zero are one of the possible solutions in this area. On the other hand, regarding economic aspects of electric vehicle (i.e. battery, charging) the public transportation system should be evaluated technically at first for creating inputs to economic models with alternative scenarios. This paper focused on demonstrating energy analysis of an electric public transportation vehicle in congested city traffic of İstanbul. In this context, diesel and an electric vehicle model was developed to demonstrate fuel and energy consumption analysis. A "dolmus" vehicle properties which are a minivan light-duty commercial vehicle used in İstanbul Public Transportation frequently is chosen for modeling. The onedimensional vehicle models are created at AVL Cruise powertrain modelling program. Then electric and diesel vehicle models were simulated with real on-road velocity profile data that was logged from the dolmuş route for $\sim 1$-hour operation. Results were compared between the conventional diesel engine and a simple electric vehicle to see transformation possibilities. Dolmus concept was transformed an electric vehicle and profits are obtained by comparing with a conventional diesel vehicle. It was also shown that one-dimensional modelling techniques can also be used to improve and optimize the electric and energetic efficiency of electric vehicles used in public transportation.
\end{abstract}

Key Words: Electric vehicle, Vehicle modelling, Energy analysis, Diesel vehicle, Simulation.

\section{INTRODUCTION}

As well known, vehicle emission legislations became primary challenge for vehicle manufacturers for last two decades. Especially for last decade strictly determined emission limits caused enormous challenge especially for diesel vehicles. Low energy request mobility is essential for a sustainable future and competitive cities where people, businesses and culture can thrive. In this context the International Association for Public Transportation (UITP) developed a vision for energy efficient transportation up until 2025 which reduces the dependency of fossil fuels. In Europe today, urban mobility consumes 140 million tons of oil equivalent per year and emits 470 million tons of carbon dioxide $\left(\mathrm{CO}_{2}\right)$ equivalent (i.e. $8 \%$ of total emissions). Public transport in urban areas is carrying 200 million people every day (i.e. $21 \%$ of total motorized mobility) and is responsible for roughly $10 \%$ of transport related greenhouse gases (GHG) emissions in cities [1].

Emission gasses has major threat on global warming due to highly increasing number of vehicles in traffic. Along with a recovering automotive industry in the European Union member states, it is forecast that increased demand for cars from customers in Asia will successfully offset tepid growth figures in South Korea and Japan, and help automobile manufacturers sell close to 80 million vehicles by the end of 2019, up from an average of less than 55 million units in the years between 2000 and 2015[2].

Emission regulations for vehicles were being restricted with parallel increasing number of vehicles. Engine out emissions became most restrain able GHG on global warming. Furthermore European Council was declared $\mathrm{CO}_{2}$ emission reduction strategies in 2030 Climate and Energy Framework as GHG emissions reduction target in Paris Agreement in 2015 The European Union (EU) became the first major economy to present its climate plan (i.e. Intended Nationally Determined Contribution or "INDC") on 6 March 2015, reflecting the 2030 climate and energy policy framework set by the October 2014 European Council and the European Commission's blueprint for tackling global climate change beyond 2020. The EU has set an ambitious economywide domestic target of at least $40 \%$ greenhouse gas emission reduction for 2030. The target is based on global projections that are 
in line with the medium term ambition of the Paris Agreement. [3]. From this perspective it is clear that clean and sustainable mobility concepts for heavily populated cities are important in terms of air pollution. In this context the usage of electric vehicles in public transportation activities which uses inner city routes are showing great importance in terms of clean mobility in living areas.

It is a well-known fact that electric motors efficiency is much higher than internal combustion engines but they are fundamentally developed with on industrial needs which is usually requires constant power (opposite to varying vehicle driving conditions). Actually internal combustion engines has too many challenges such as vibration, heating problems, exhaust gas, complex working principle so on. But internal combustion engines has huge reliability background that comes from 100 years. On the other hand electric motors have many profits that can be assumed as outstanding option for many vehicles. They can easily deliver maximum desired torque in very wide range which is biggest plus than combustion engines. As a reason of efficiency their cooling requirements are less then engines furthermore new engines cooling requirements are coverable with air and efficiencies are going higher every day. Biggest challenge about electric vehicles is for sure battery systems. Battery is outstanding handicap to replace combustion engines. Their energy capacities are less than fossil fuels thus energy storage abilities causes limited ranges. Biggest battery capacities causes weightiness and volume in vehicles which requires more energy and packaging tasks. Usually in most of electric vehicles uses lithium ion battery's which consist of many individual cells. They can be controlled with an algorithm called Battery Management System to improve energy efficiency during driving conditions.

This research has focused on one of most congested city Istanbul which has huge mobility 5.7 million people every day. Mobility concept has chosen mostly preferred light duty diesel vehicles called "dolmuş" which uses high traffic routes during rush hour Electric vehicles efficiency is an obvious advantage realize transformation public transportation concepts. Besides this transformation needs well designed infrastructure to get sustainable transportation system.

In this context a diesel and electric one dimensional "dolmuş" vehicle model was developed in AVL Cruise simulation environment.[3]. Then the model was run with logged time dependent velocity data from on road testing and fuel consumption and $\mathrm{CO}_{2}$ data was analyzed. Then the electric dolmuş vehicle model was run with same speed profile and the results was analyzed and compared with diesel vehicle simulation results. Then results are analyzed in terms of energetic efficiencies and tank to wheel emissions.

\section{METHODOLOGY}

\subsection{Fuel Consumption Modelling}

Vehicle fuel consumption and emission models are currently the primary tools for evaluating the regional impacts of transportation projects and in evaluating developed transportation technologies. These simulation methodologies were classified into two main categories by Faris Et.al [6]. These are a) Scale of Input Variable-based modelling (SIVM) Formulation Approachbased Modelling (FAM). One of the main sub-modelling category of the SIVM is Microscopic Modeling (MIM) that estimate instantaneous vehicle fuel consumption and emissions. The instant vehicle characteristics and road conditions are needed in this modelling methodology [4]. The modelling technology used in this paper can be classified as a MIM modeling. The workflow is given at Figure 1. It can be summarized as vehicle specification based on vehicle concept, recording fuel consumption from on board diagnostic (OBD), building up a two vehicle models for both options as electric vehicle (EV) and internal combustion engine (ICE) vehicle, verifying suitability with reference data, simulation running with dolmuş speed profiles and get results as energy consumption and energy loss. 


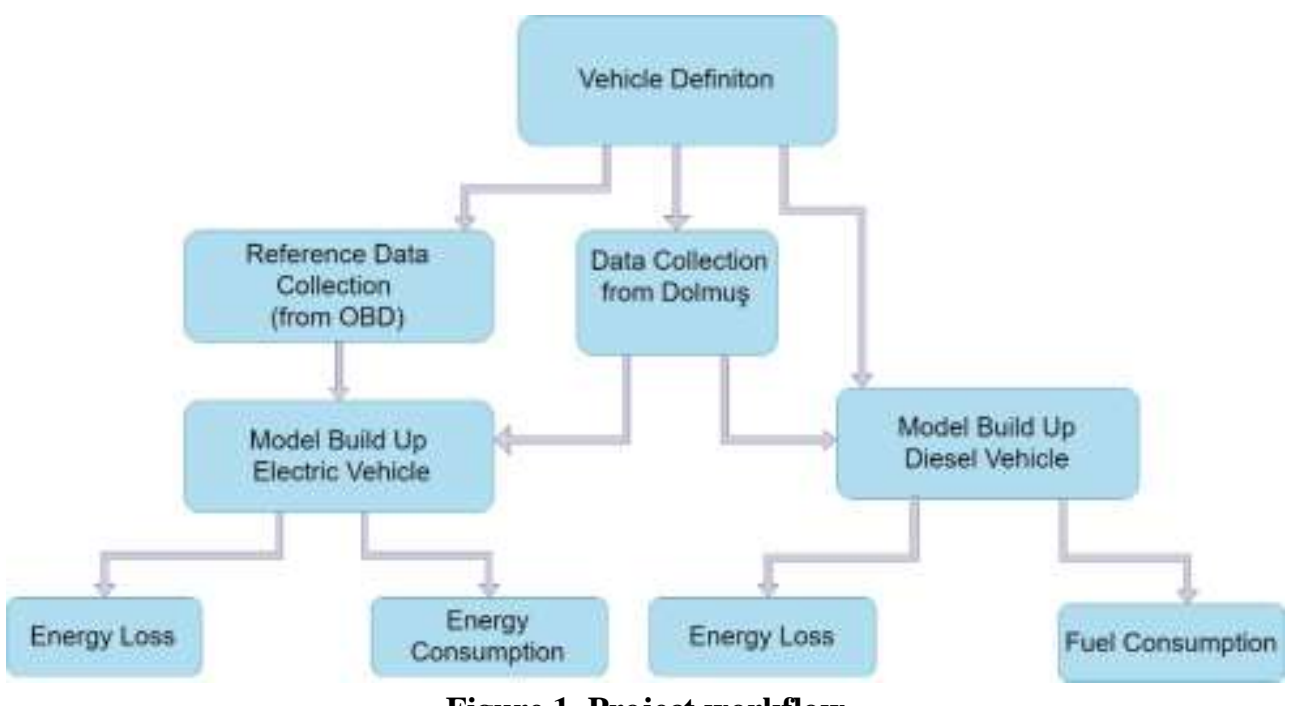

Figure 1. Project workflow

As mentioned before, two models were built to demonstrate energy efficiency analysis. The difference will be resulted as fuel consumption for ICE vehicle, cumulative fuel consumption can be used to estimate $\mathrm{CO}_{2}$ release which is highlighted results for analysis.

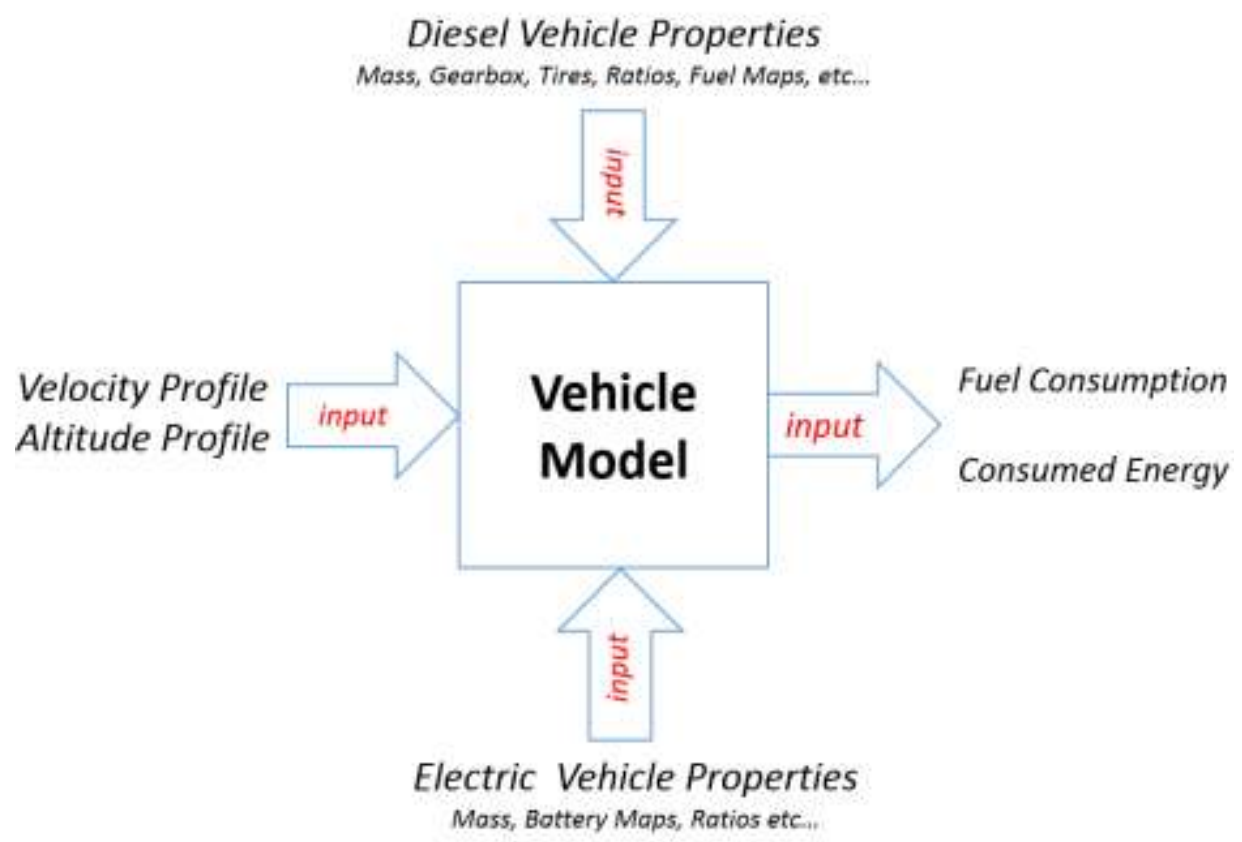

Figure 2. Methodology

Conventional diesel model is built with taking as diesel minivan vehicle as reference and all components are modelled and with same specifications. While building up electric vehicle model vehicle specifications kept as same such as wheels, center of mass, frontal area etc, and powertrain is transformed to an Electric vehicle with electric motor and battery. Both models are simulated with cycle which has velocity and altitude profile and energy analysis is made with simulation outputs fuel consumption for diesel vehicle, battery consumption for EV. The modelling methodology is given in Figure 2.

\subsection{Vehicle Modelling}

The modelled vehicle properties is given in Table 1. Also the vehicles photo waiting at the takeoff station is given in Figure 1. The two developed models in AVL Cruise environment is given in Figure 4 and 5 respectively for diesel and electric vehicle. The main goal to develop a realistic conventional diesel vehicle and EV model that can demonstrate inhabitable $\mathrm{CO} 2$ release, fuel and energy consumption based on cycle. 
International Journal of Engineering Research And Advanced Technology, Vol.5, Issue 4, April-2019

Table 1. Vehicle and Engine Properties

\begin{tabular}{|l|l|}
\hline Vehicle Weight & 2 tones \\
\hline Vehicle Type & Minivan \\
\hline Number of seats & 10 \\
\hline Frontal Area & $2,52 \mathrm{~m}^{2}$ \\
\hline Wheel Size & $215 / 65 \mathrm{R} 15$ \\
\hline Engine Type & 2L Diesel \\
\hline Number of cylinders & 4 \\
\hline Transmission & Auto Transmission 6 Gears \\
\hline Emission Certification Level & Euro 5 \\
\hline
\end{tabular}

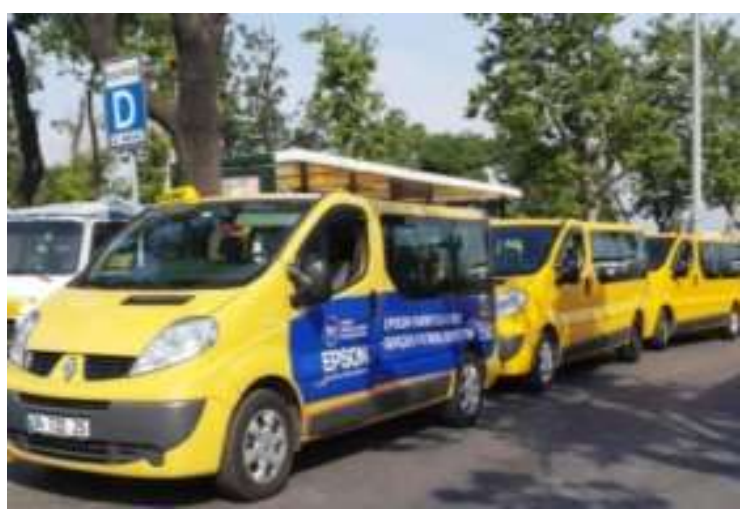

Figure 3. Dolmuş vehicles waiting at the take off station.

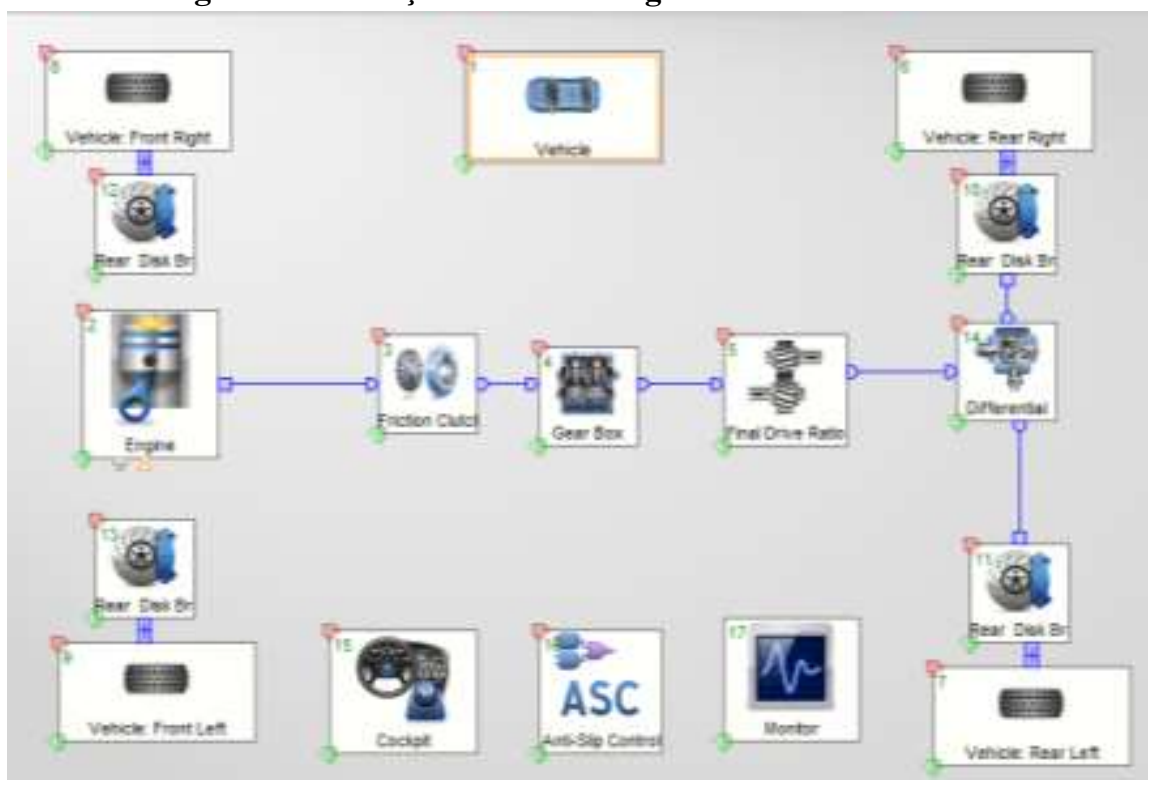

Figure 4. Internal combustion engine model overview in AVL Cruise 


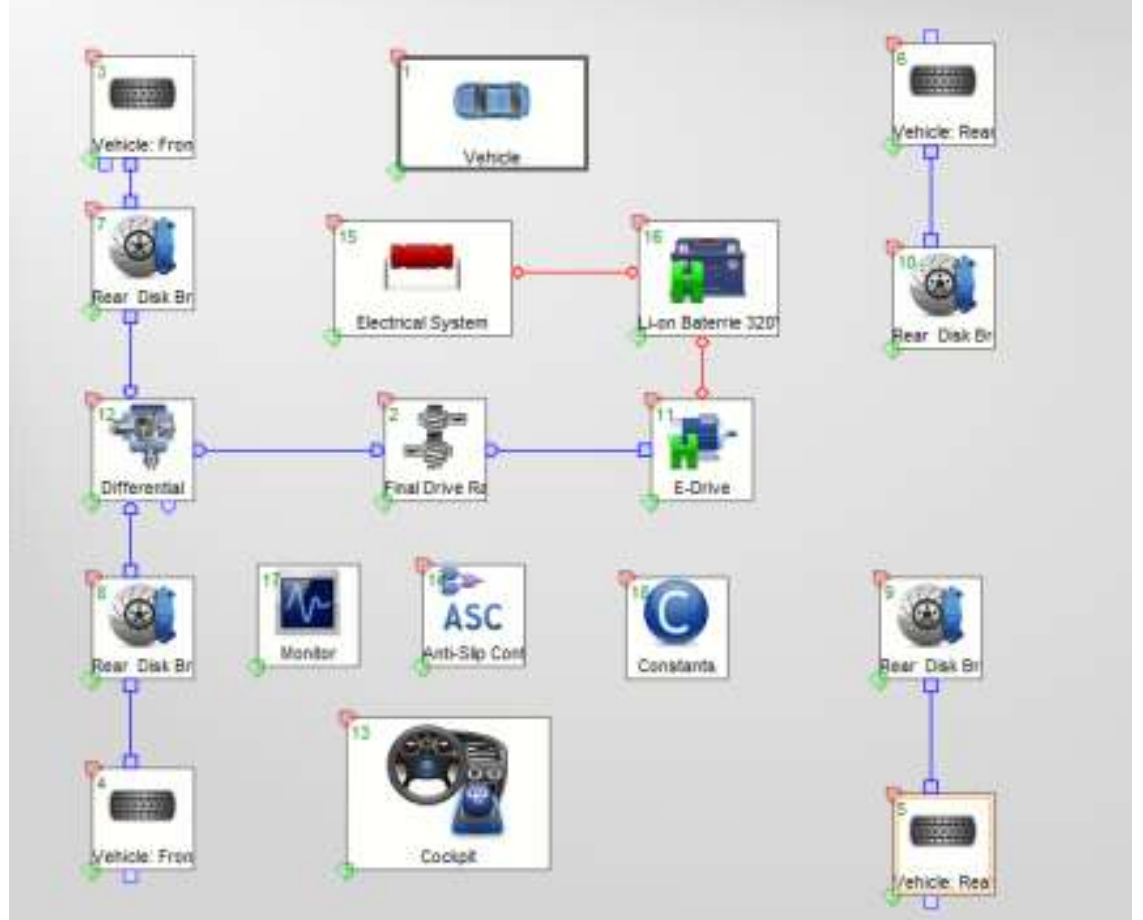

Figure 5. Electric vehicle model overview in AVL Cruise

The fundamental model results of AVL Cruise is calculated from driving resistances which occurs in driving conditions. Sum of driving resistances effect of vehicle motion in reverse direction of which is named as running resistance $(F \mathrm{~W})$. Basically running resistances in other words "driving resistances" are claimed as three types rolling resistance (FRo), aerodynamic resistance $(F \mathrm{~L})$ and climbing resistance $(F \mathrm{St})$ as described in Formula 1.2, Formula 1.3 and Formula 1.4. The simulation and measurement fuel consumption

$$
\begin{aligned}
& F_{\mathrm{W}}=F_{\mathrm{Ro}}+F_{\mathrm{L}}+F_{\mathrm{St}} \\
& F_{\mathrm{Ro}}=f \cdot G=f \cdot m \cdot g \\
& F_{\mathrm{L}}=0.5 \cdot \rho \cdot c_{\mathrm{W}} \cdot A(v+v 0)^{2} \\
& F_{\mathrm{St}}=G \cdot \sin \alpha=m \cdot g \cdot \sin \alpha
\end{aligned}
$$

The battery-to-wheel consumption of an electric vehicle is a function of the required mechanical energy at the wheels, determined by the kinematic parameters over a trajectory, the drivetrain efficiency, and the energy consumption of auxiliaries. The total required mechanical energy at the wheels as a function of the kinematic parameters describing vehicle movement can be expressed in the vehicle dynamics equation in 1.5 [5]

$$
\left.E_{i j}=\frac{1}{3600}\left[m_{i j} \cdot g(f \cdot \cos \varphi+\sin \varphi)+0.0386\left(\rho \cdot C_{x} \cdot A \cdot\right) v_{i j}{ }^{2}\right)+\left(m_{i j}+m_{f}\right) \frac{d v}{d t}\right] \cdot d_{i j}
$$

\section{RESULTS AND DISCUSSIONS}

\subsection{Velocity and Elevation Profile}

The time based speed and altitude profile was logged with a mobile device. The total operating duration logged during this event is 1 hour (including resting times at stations). Total travelled distance during one day operation is analyzed as $90 \mathrm{~km}$. The average travelling time for dolmuş operations are identified as 12 hours a day and average $180 \mathrm{~km}$ for one day operations. Results are analyzed with using a $\sim 17 \mathrm{~km}$ cycle. The altitude and speed variance as shown in Figure 6. 


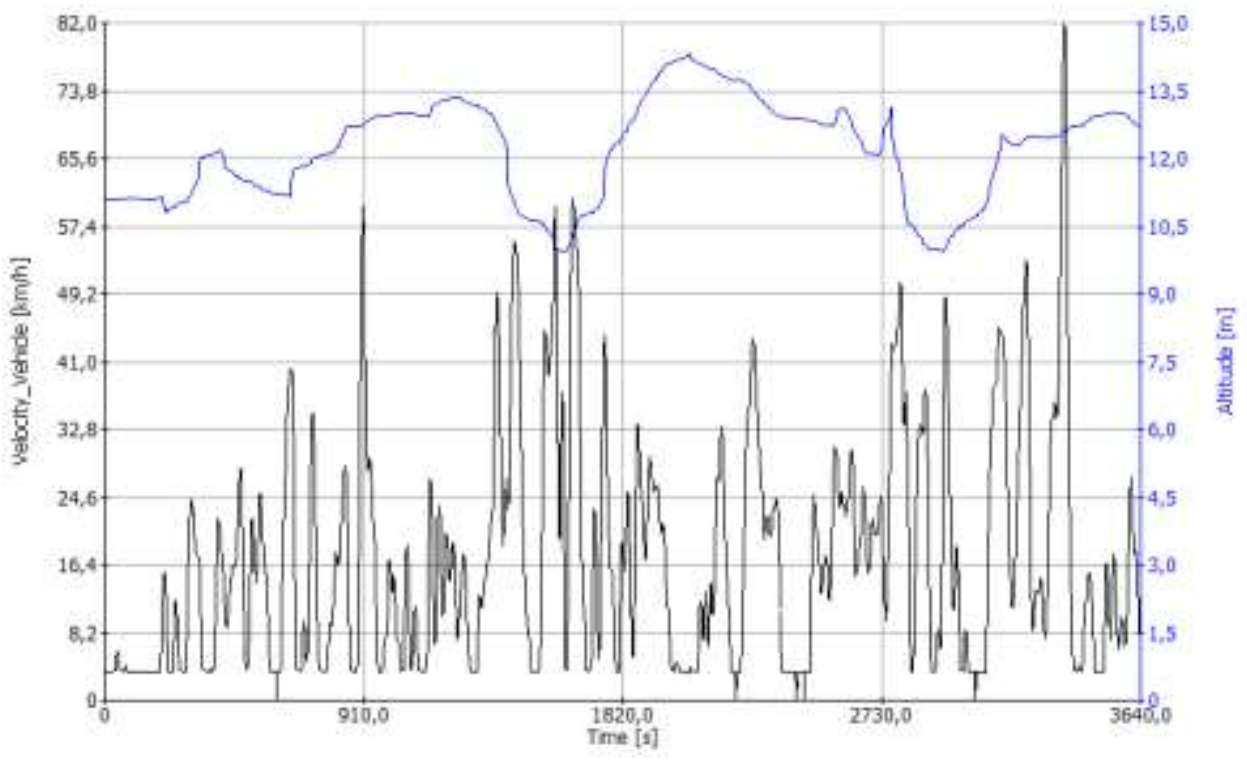

Figure 6. Dolmuş driving cycle elevation and velocity profile

\subsection{Simulation Result of Conventional Diesel Vehicle}

Fuel consumption is most preferred and representative output for energy consumption analysis. It is a respectable output to demonstrate to consumed energy source can be converted to energy with universally accepted formulations and mechanical energy formulation can be used to obtain effective energy during driving cycle. In Figure 7 cumulated fuel consumption for 1 hour dolmuş operation shown as 2,5 liters. Fuel consumption will be changed with traffic situation and driving behaviors relatively however as a basic calculation with an assumption, approximately 12 hours operation in a day, total cumulative fuel consumption reaches approximately 30 liters daily. Annually it can be calculated as 10.950 liters. Based on assumption air excess ration $(\lambda)>1$, fuel contains approximately $\% 85 \mathrm{C}$, it was calculated that this amount of fuel would release 25.422,65 $\mathrm{kg} \mathrm{CO}_{2}$ approximately during annual operation.

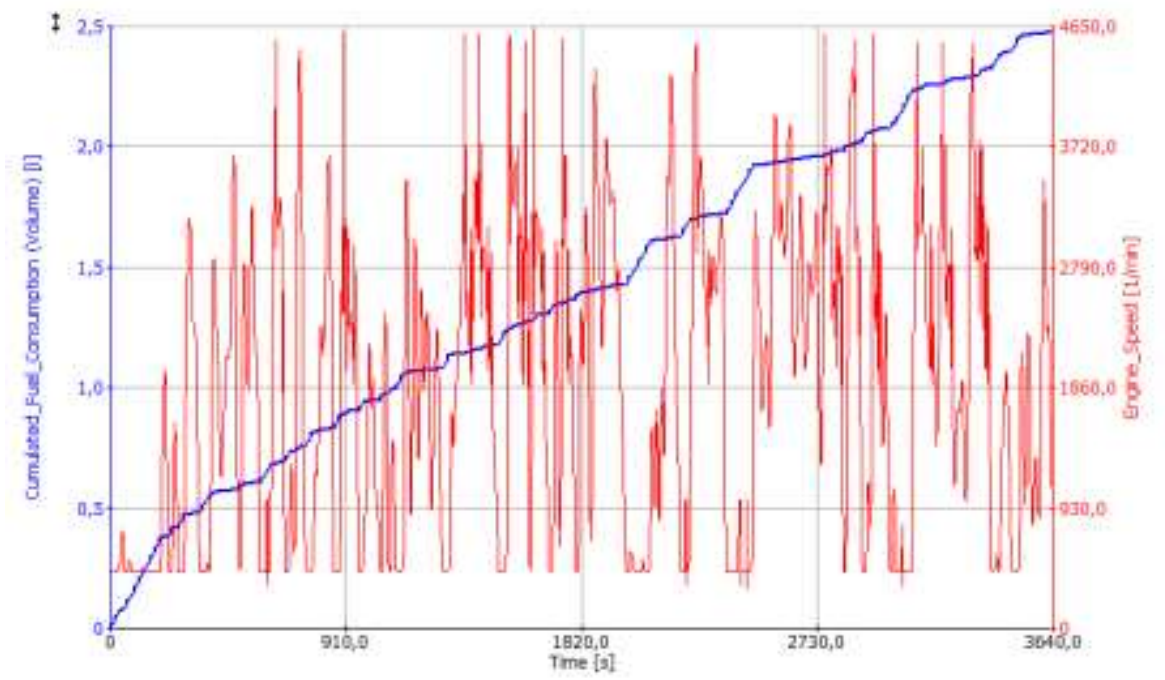

Figure 7. Cumulative and specific fuel consumption in diesel vehicle during trip

When Figure 6 is analyzed velocity oscillations can be seen clearly, it is caused various load requirements throughout the cycle. It leads to change engine operating point frequently which requires different fuel consumptions depending on torque and engine speed points as shown in Figure 8. It can be also seen from this graphic the vehicle is generally used part load points because of heavy traffic conditions. If we focus on cumulated fuel consumption line during cycle which is shown with blue, fuel consumption gradient is not seen in a stabilized. Especially fuel consumption gradients increases considerably while braking. 


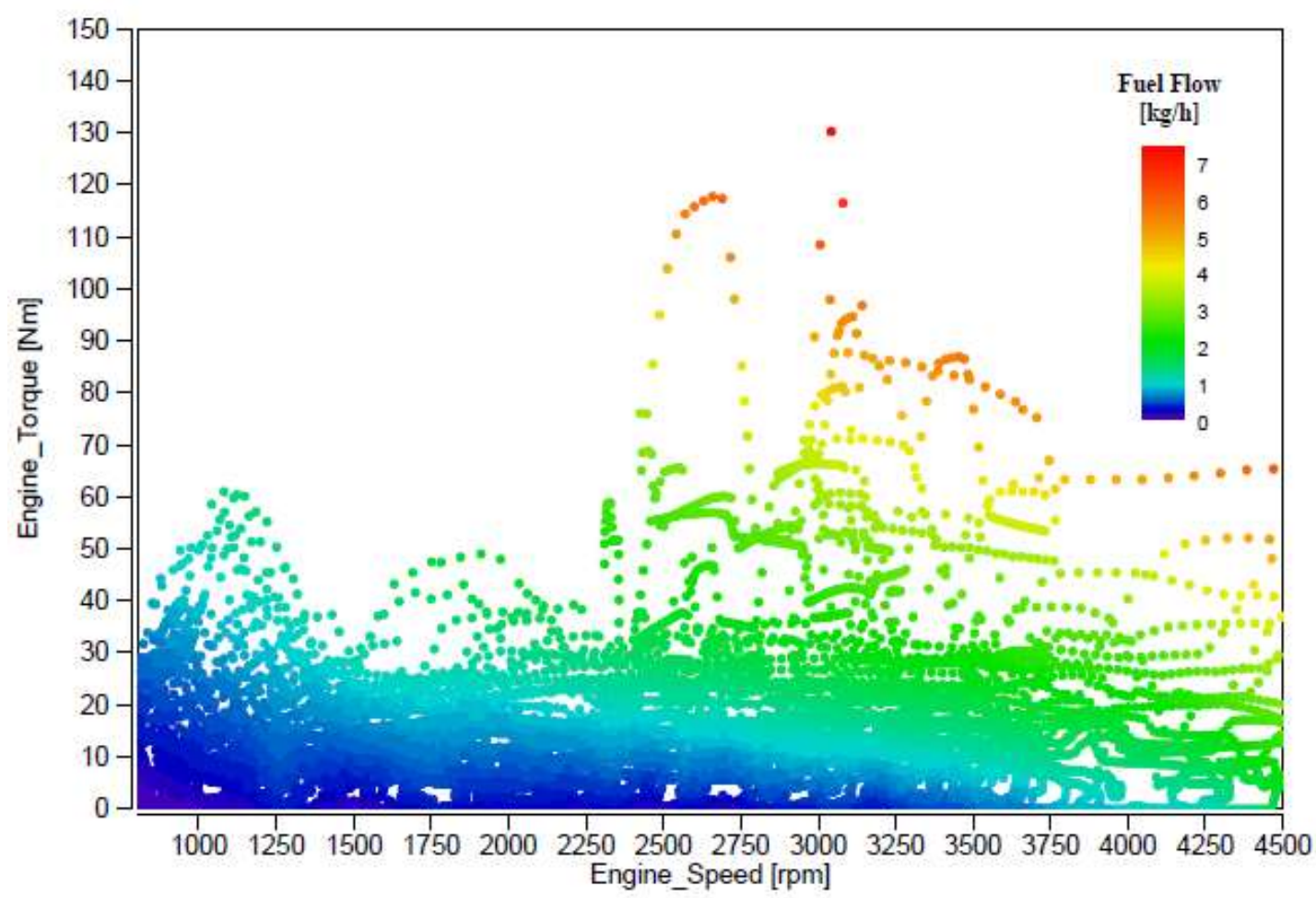

Figure 8. Fuel consumption rates during driving cycle.

\subsection{Simulation Result of Electrical Vehicle}

EV model is built in AVL Cruise and simulated with same speed and altitude profile shown in Figure 6. Main output of model is energy consumption and electric power trace can be seen in Figure 9. In contrast with diesel model, energy consumption gradient increases with higher loads and goes rather lower gradient when the vehicle slows down the main difference between two models is energy direction while braking. In diesel vehicles mechanical energy transforms to mechanical energy from brakes, oppositely in EVs this released energy can be recovered and feeds electric battery with regenerative braking systems. Regenerative braking is not integrated in this model to demonstrate advantages with a basic EV model which is rather low efficiency.

As seen in Figure 9, calculated total energy output for the same cruise is equal to approximately $13.800 \mathrm{~kJ}$ energy in EV model, which equals to $3,83 \mathrm{kWh}$ in 1 hour driving cycle. In same calculation which is made on diesel vehicle model, energy consumption of this vehicle is $46 \mathrm{kWh}$ approximately with 12 hours operation. It corresponds $16.775 \mathrm{kWh}$ annually.

In this context, while the tank to wheel emissions are zero for inner city routes with the advantage of electric vehicle, the well to wheel emissions should be analyzed. For future well to wheel $\mathrm{CO}_{2}$ evaluation the electricity generation type should be analyzed. There has not yet been any broadly accepted approach for assessing the $\mathrm{CO} 2$ emissions from power plants which are caused by the additional electricity demand from EV during their usage phase. For a comprehensive evaluation, the whole electricity the whole electricity generation system should be considered [9]. Considering to the energy is produced from natural gas combustion at the plant, the $\mathrm{CO}_{2}$ foot print would be in $\sim 500 \mathrm{gCO}_{2} \mathrm{eq} / \mathrm{kWh}$ [10]. So the annual $\mathrm{CO}_{2}$ footprint of an EV that is completely supplied with a natural gas plant can be calculated as $8387,5 \mathrm{~kg}$ of $\mathrm{CO}_{2}$ with the accepting of $35 \%$ thermal efficiency at the plant. The $\mathrm{CO}_{2}$ foot print for nuclear plant is given as $<5 \mathrm{gCO} 2 \mathrm{eq} / \mathrm{kWh}$ at [10]. Taking it as equal to $5 \mathrm{gCO} 2 \mathrm{eq} / \mathrm{kWh}$ the value the $\mathrm{CO}_{2}$ footprint, it be calculated as $83,87 \mathrm{~kg} \mathrm{CO} 2$ from nuclear energy plant. 


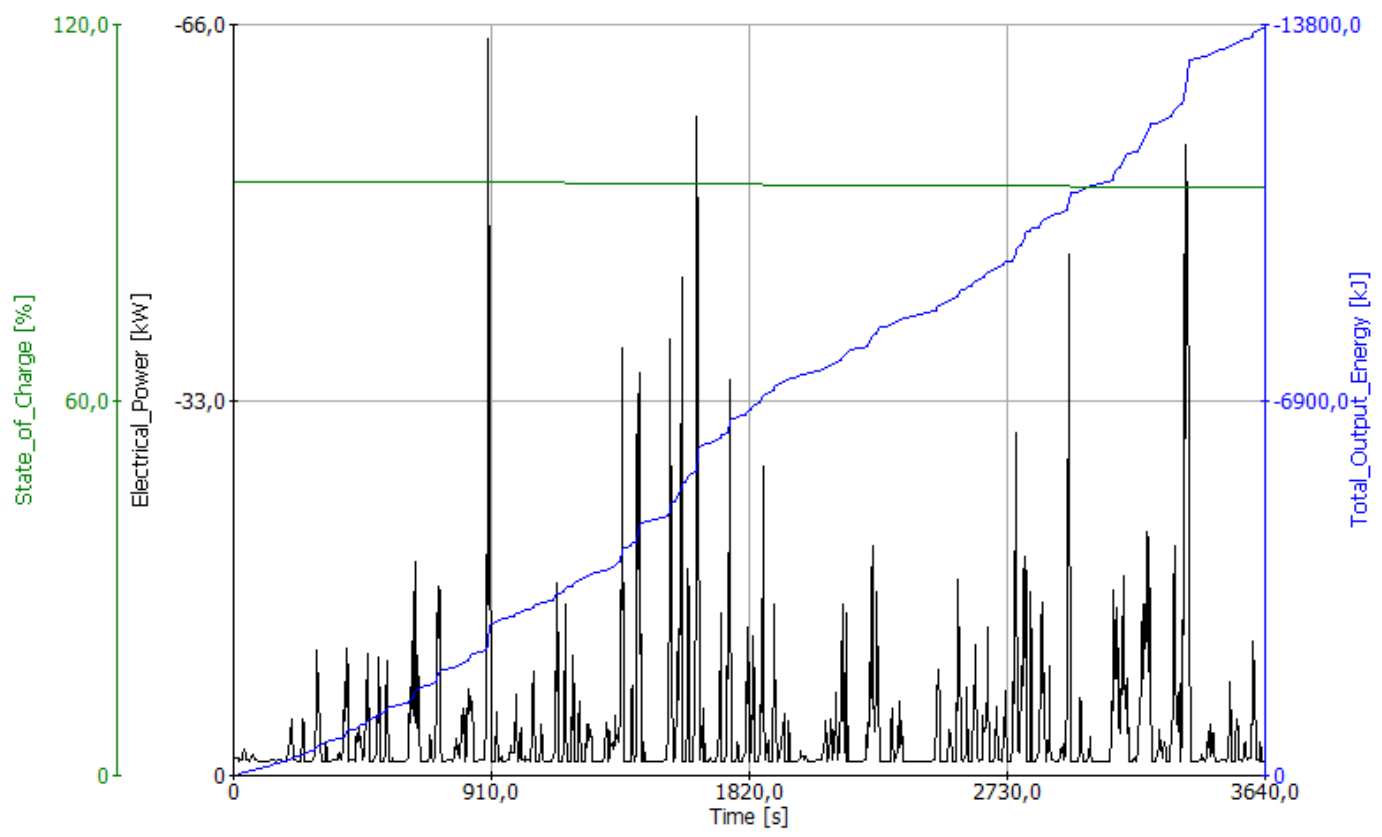

Figure 9. Total energy consumption of electrified dolmuş by time

\section{CONCLUSION}

A comprehensive one dimensional modelling is presented for diesel and electric vehicle powertrains for dolmuş public transportation vehicle in İstanbul. The two powertrain architecture is modelled in AVL Cruise environment in detail. A one hour data on road data in terms of velocity and altitude is logged from dolmuş transportation route. Then the two model were run with this target data. The fuel consumption, torque speed and $\mathrm{CO}_{2}$ release characteristics of diesel powertrain vehicle and energetic outputs of electric vehicle are analyzed from this perspective. From tank-to-wheel perspective the electric powertrain is showing more energy and environmental efficient potential than the diesel powertrains. In this context; it was evaluated that vehicle electrification is one of the strategy with higher potential for reducing the dependency on dwindling fossil fuel sources and meeting stringent emissions targets set by policy makers of metropolitan cities. It is showing a great potential to reduce air pollution arouse from transportation on the central city roads which a huge habitants is living. On the other hand for future and more comprehensive work the tank to wheel and well to wheel analyzes should be carried out in detail for a complete analyze with considering the energy production plant properties.

\section{REFERENCES}

1. UITP, "Towards low/zero-carbon urban mobility in Europe, International Association of Public Transport." (2011)

2. International car sales statistics, https:/www.statista.com/statistics/200002/international-car-sales-since-1990/

3. AVL Cruise webpage, https://www.avl.com/cruise

4. European Comission, Communication From The Commission To The European Parliament And The Council, "The Road from Paris: assessing the implications of the Paris Agreement and accompanying the proposal for a Council decision on the signing, on behalf of the European Union, of the Paris agreement adopted under the United Nations Framework Convention on Climate Change" (2016)

5. L F. Leite Leirião* , S G El Khouri Miraglia, "Environmental and health impacts due to the violation of Brazilian emissions control program standards in Sao Paulo Metropolitan Area", (2019)

6. W.Faris, H Rakh,S A.M. Elmoselhy "Impact of Intelligent Transportation Systems on Vehicle Fuel Consumption and Emission Modeling: An Overview".Sae International (2014),

7. C Cauwer *, J.V Mierlo, T.Coosemans ," Energy Consumption Prediction for Electric Vehicles Based on Real-World Data” (2015)

8. United States Enviromental Protection Agency, "Average Carbon Dioxide Emissions Resulting from Gasoline and Diesel Fuel", 2005

9. P Jochem,.S. Babrowski, “Assessing CO2 Emissions of Electric Vehicles in Germany 2030” Science Direct, 2015

10. Parliamentary Office of Science and Technology, "Carbon Footprint Of Electricity Generation”, (2006) 